Article

\title{
Effect of Glutathione Bio-Molecule on Tooth Discoloration Associated with Silver Diammine Fluoride
}

\author{
Mahmoud Sayed ${ }^{1}$, Naoko Matsui ${ }^{2, *}$, Noriko Hiraishi ${ }^{3}$, Toru Nikaido ${ }^{2}$, Michael F. Burrow ${ }^{4}$ \\ and Junji Tagami ${ }^{2}$ \\ 1 Cariology and Operative Dentistry, Graduate School of Medical and Dental Sciences, Tokyo Medical and \\ Dental University, 113-8510 Tokyo, Japan; Drmahmoudmacklad@gmail.com \\ 2 Cariology and Operative Dentistry, Oral Restitution Department, Graduate School of Medical and Dental \\ Sciences, Tokyo Medical and Dental University, 1-5-45, Yushima, Bunkyo-ku, 113-8549 Tokyo, Japan; \\ nikaido.ope@tmd.ac.jp (T.N.); tagami.ope@tmd.ac.jp (J.T.) \\ 3 Research Fellow of Japan Society for the Promotion of Science, Tokyo Medical and Dental University, \\ 113-8510 Tokyo, Japan; hiraope@tmd.ac.jp \\ 4 Faculty of Dentistry, University of Hong Kong, Hong Kong, China; mfburrow@unimelb.edu.au \\ * Correspondence: Matsui.ope@tmd.ac.jp; Tel.: +81-(0)3-5803-5483; Fax: +81-(0)3-5803-0195
}

Received: 20 February 2018; Accepted: 26 April 2018; Published: 29 April 2018

\begin{abstract}
This study evaluated the effect of Glutathione (GSH) bio-molecule on the reduction of enamel and dentin discoloration after application of $38 \%$ silver diammine fluoride solution (SDF). One hundred and twenty bovine teeth specimens were used. The enamel and dentin specimens were divided into three groups: (1) SDF only (control); (2) SDF followed by application of a potassium iodide solution (KI); and (3) SDF mixed with $20 \%$ GSH. Half the specimens were exposed to light and the remainder kept in dark conditions $(n=10)$ Color changes were measured using a spectrophotometer at the following time intervals: before solution application (baseline) and immediately after application, then 3, 6, 24, 48, 72 h, and 7, 10 and 14 days. SEM/EDS analysis was performed on treated enamel and dentin. Statistical analysis was done using a repeated measures ANOVA test. The spectrophotometer results showed that the SDF group exhibited the greatest color changes under both light exposed and dark conditions, while SDF + GSH group was effective in decreasing the color changes in both light and dark conditions. The SDF + KI group showed an insignificant color changes over time. SEM/EDS analysis showed different patterns for the silver crystal formation in each group (SDF, SDF + GSH, and SDF + KI group). It was concluded GSH can effectively minimize color changes after application of SDF, especially on enamel and to a lesser extent on dentin.
\end{abstract}

Keywords: silver diammine fluoride; glutathione; discoloration; spectrophotometer

\section{Introduction}

Dental caries is a prevalent bacterial, multifactorial, dynamic disease caused by an imbalance between demineralization and remineralization processes of tooth structure. It is considered one of the most common diseases affecting humans [1]. Different cost effective preventive measures are needed as a mean to reduce the effects of dental caries such as pain, and loss of natural teeth [2].

Silver compounds, like silver nitrate and silver fluoride, have been used in dental treatments over many years. Their use commenced with the management of dental caries in deciduous teeth, which then progressed as a preventive agent on permanent teeth [3]. Being introduced by Yamaga et al., in the late 1960's [4], silver diammine fluoride (SDF) is one of these silver compounds on which experiments 
have been conducted with promising results documented in the literature showing its ability to protect against and arrest dental caries $[2,5,6]$.

SDF is considered as an efficient, cost effective, and non-invasive material that can be used on deciduous and permanent teeth. It has been demonstrated to have a unique anti-bacterial effect and can inhibit demineralization and increase the surface micro-hardness of the tooth structure [5]. SDF is proven to be more effective in caries prevention compared to fluoride varnish [6], where it has been shown to lead to $70 \%$ of caries lesions arresting compared to $46 \%$ for fluoride varnish. Annual and biannual applications of SDF can significantly reduce the development of new lesions, offering high effectiveness in protection against caries at low cost. [7].

However, the main drawback of SDF is the formation of dark stains on tooth structure. This unpleasant outcome limits its clinical use [8] due to aesthetic concerns.

Application of potassium iodide (KI) after SDF results in a creamy white precipitate of silver iodide (AgI), which is considered as one of the methods that can overcome the staining problem [9]. However, recently it was noticed that the color improvement with KI is only temporary and the darkening of tooth surfaces still occurs [10,11]. In addition, the use of SDF and KI together reduces free silver ions [9], which may decrease the merits of SDF dramatically, most likely over the long term.

An alternative method has been developed which may decrease staining from SDF and preserve the silver within the solution and on the substrate surface by mixing glutathione with SDF, which will be investigated in this paper

Glutathione (GSH) is considered one of the most common intracellular non-protein thiols (NPSH) that acts as a reducing agent in mammalian cells. NPSH is an anti-oxidant that can act as a metal chelator and radical quencher [12].

GSH has been previously used as a biomimetic coating on silver particles to enhance interactions with complex bio-systems and increase its water solubility $[13,14]$.

The aim of this study was to evaluate the effect of glutathione bio-molecule on the degree of enamel and dentin discoloration after application of silver diammine fluoride (SDF), with and without light exposure at different time intervals. The null hypothesis in this study is GSH has no effect on the color changes of enamel and dentin after application of SDF.

\section{Results}

\subsection{Spectrophotometric Measurement of Color Changes}

A repeated measure ANOVA was conducted to compare the different tested groups for color changes $(\Delta \mathrm{E})$ of the dentin surface over a 14-day time interval. The data were obtained immediately, 3, 6 , 24 and $72 \mathrm{~h}$ followed by 7, 10 and 14 days. Mauchly's test indicated that the assumption of sphericity had been violated; therefore, the Greenhouse-Geisser corrected tests were used. There was a significant interaction between time and groups at $\mathrm{F}(19.517,172.8)=31.159, p \leq 0.001$. Post hoc comparisons indicated that there was a difference among the tested groups at all time periods $(p \leq 0.001)$.

In the light exposed enamel groups, GSH showed a strong influence in reducing the color changes $(\triangle \mathrm{E})$ of enamel after application of SDF, while the SDF group showed the greatest color changes compared to the other groups at all time periods. The SDF + KI group showed a minor immediate color changes which darkened insignificantly over the two weeks of observations (Table 1 and Figure 1).

The dark stored enamel groups showed the same pattern as the light exposed groups, however at lower values of $\Delta \mathrm{E}$ with the SDF + GSH group showed improvement in the esthetic outcome (Table 2 and Figure 2). 
Table 1. Mean and standard deviation (SD) for the color change $(\Delta \mathrm{E})$ for different tested groups at all time intervals within enamel under light exposed conditions.

\begin{tabular}{cccccccc}
\hline \multirow{2}{*}{ Enamel } & \multicolumn{5}{c}{ Exposed to Light (Wavelength 410-460 nm) } & \multirow{2}{*}{$p$-Value } \\
\cline { 2 - 6 } & \multicolumn{2}{c}{ SDF } & \multicolumn{4}{c}{ SDF + GSH } & \multicolumn{2}{c}{ SDF + KI } & \\
\cline { 2 - 6 } & Mean & SD & Mean & SD & Mean & SD & \\
\hline Immediate & $4.68^{\mathrm{a}}$ & 1.44 & $1.20^{\mathrm{b}}$ & 0.34 & $4.65^{\mathrm{a}}$ & 0.84 & $\leq 0.001^{*}$ \\
$3 \mathrm{~h}$ & $14.17^{\mathrm{a}}$ & 3.05 & $2.17^{\mathrm{c}}$ & 0.58 & $5.28^{\mathrm{b}}$ & 0.71 & $\leq 0.001^{*}$ \\
$6 \mathrm{~h}$ & $21.95^{\mathrm{a}}$ & 3.53 & $3.32^{\mathrm{b}}$ & 0.71 & $5.51^{\mathrm{b}}$ & 0.81 & $\leq 0.001^{*}$ \\
$24 \mathrm{~h}$ & $34.52^{\mathrm{a}}$ & 1.93 & $7.62^{\mathrm{b}}$ & 2.11 & $6.23^{\mathrm{b}}$ & 0.86 & $\leq 0.001^{*}$ \\
$48 \mathrm{~h}$ & $40.32^{\mathrm{a}}$ & 2.40 & $9.76^{\mathrm{b}}$ & 2.29 & $6.55^{\mathrm{c}}$ & 1.06 & $\leq 0.001^{*}$ \\
$72 \mathrm{~h}$ & $42.62^{\mathrm{a}}$ & 2.38 & $10.94^{\mathrm{b}}$ & 2.07 & $6.90^{\mathrm{c}}$ & 1.42 & $\leq 0.001^{*}$ \\
7 days & $43.81^{\mathrm{a}}$ & 3.27 & $13.03^{\mathrm{b}}$ & 2.46 & $7.08^{\mathrm{c}}$ & 1.97 & $\leq 0.001^{*}$ \\
10 days & $45.68^{\mathrm{a}}$ & 4.06 & $13.98^{\mathrm{b}}$ & 2.54 & $6.88^{\mathrm{c}}$ & 1.24 & $\leq 0.001^{*}$ \\
14 days & $46.77^{\mathrm{a}}$ & 3.45 & $14.76^{\mathrm{b}}$ & 2.35 & $6.99^{\mathrm{c}}$ & 1.39 & $\leq 0.001^{*}$ \\
\hline
\end{tabular}

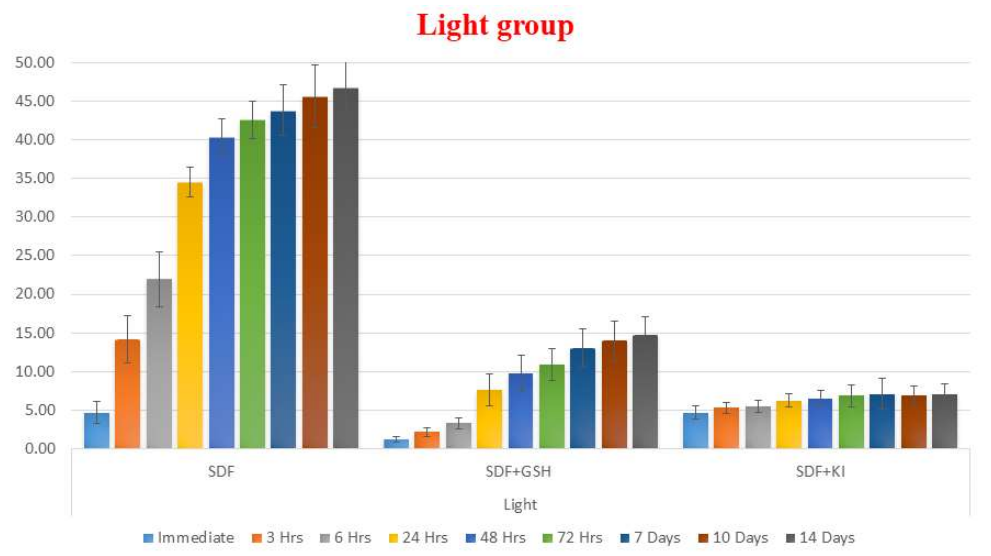

Figure 1. Bar chart showing mean $\Delta \mathrm{E}$ for different tested groups for enamel substrate within each time interval under light exposed conditions.

Table 2. Mean and SD for $\Delta \mathrm{E}$ for different tested groups at all time intervals within enamel under dark conditions.

\begin{tabular}{cccccccc}
\hline \multirow{2}{*}{ Enamel } & \multicolumn{6}{c}{ Dark } & \multirow{2}{*}{$p$-Value } \\
\cline { 2 - 6 } & \multicolumn{2}{c}{ SDF } & \multicolumn{9}{c}{ SDF + GSH } & \multicolumn{2}{c}{ SDF + KI } & \\
\cline { 2 - 6 } & Mean & SD & Mean & SD & Mean & SD & \\
\hline Immediate & $2.63^{\mathrm{b}}$ & 0.88 & $2.01^{\mathrm{b}}$ & 0.52 & $4.36^{\mathrm{a}}$ & 1.03 & $\leq 0.001^{*}$ \\
$3 \mathrm{~h}$ & $2.79^{\mathrm{b}}$ & 0.99 & $1.64^{\mathrm{b}}$ & 0.54 & $5.29^{\mathrm{a}}$ & 1.09 & $\leq 0.001^{*}$ \\
$6 \mathrm{~h}$ & $2.61^{\mathrm{b}}$ & 0.83 & $2.61^{\mathrm{b}}$ & 0.89 & $5.36^{\mathrm{a}}$ & 1.01 & $\leq 0.001^{*}$ \\
$24 \mathrm{~h}$ & $4.66^{\mathrm{ab}}$ & 1.66 & $3.23^{\mathrm{b}}$ & 0.92 & $5.68^{\mathrm{a}}$ & 1.28 & $0.009^{*}$ \\
$48 \mathrm{~h}$ & $5.65^{\mathrm{ab}}$ & 1.91 & $4.13^{\mathrm{b}}$ & 0.67 & $6.13^{\mathrm{a}}$ & 1.23 & $0.033^{*}$ \\
$72 \mathrm{~h}$ & 6.95 & 2.37 & 4.95 & 1.02 & 6.46 & 1.50 & $0.117 \mathrm{NS}$ \\
7 days & 8.35 & 2.67 & 5.86 & 1.53 & 6.25 & 1.58 & $0.134 \mathrm{NS}$ \\
10 days & $11.02^{\mathrm{a}}$ & 2.39 & $6.55^{\mathrm{b}}$ & 1.20 & $6.74^{\mathrm{b}}$ & 1.60 & $0.003^{*}$ \\
14 days & $11.87^{\mathrm{a}}$ & 2.32 & $7.45^{\mathrm{b}}$ & 1.56 & $6.91^{\mathrm{b}}$ & 1.73 & $0.004^{*}$ \\
\hline
\end{tabular}

Means with the same letter $(\mathrm{a}, \mathrm{b}$ or $\mathrm{ab})$ within each row are not significant (NS), and $\left(^{*}\right)$ means significant at $p>0.05$. 


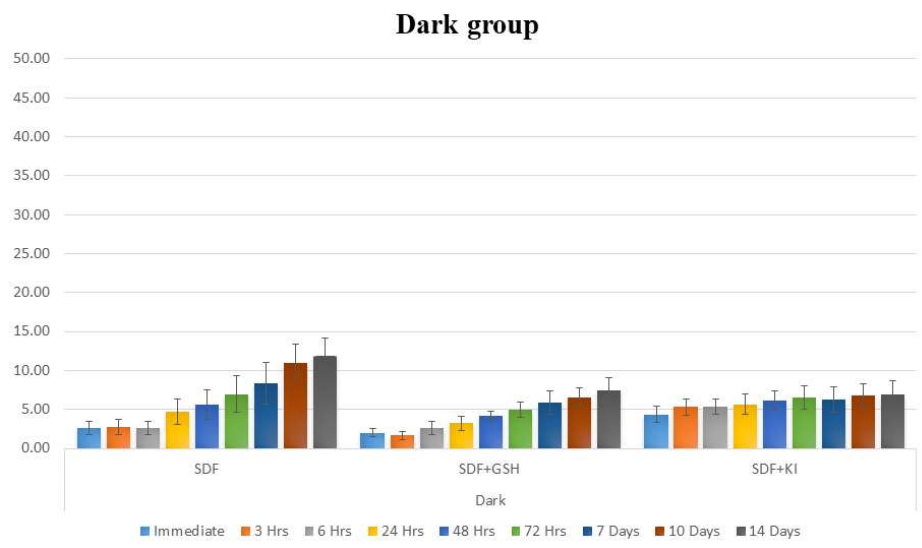

Figure 2. Bar chart showing mean $\Delta \mathrm{E}$ for different tested groups for enamel substrate within each time interval under dark conditions.

In the dentin groups exposed to light, GSH reduced the color changes but it was less than that for enamel, while SDF also showed the highest $\Delta \mathrm{E}$ values and SDF $+\mathrm{KI}$ group showed the largest change in color immediately after solution application but after two weeks, it showed the least overall change in color (Table 3 and Figure 3).

Table 3. Mean and $\mathrm{SD}$ for $\Delta \mathrm{E}$ for different tested groups at all the time intervals within dentin under light exposed conditions.

\begin{tabular}{|c|c|c|c|c|c|c|c|}
\hline \multirow{3}{*}{ Dentin } & \multicolumn{6}{|c|}{ Light } & \multirow{3}{*}{$p$-Value } \\
\hline & \multicolumn{2}{|c|}{ SDF } & \multicolumn{2}{|c|}{ SDF + GSH } & \multicolumn{2}{|c|}{ SDF + KI } & \\
\hline & Mean & SD & Mean & SD & Mean & SD & \\
\hline Immediate & $2.47^{b}$ & 0.57 & $3.38^{\mathrm{a}}$ & 1.18 & $4.50^{\mathrm{a}}$ & 1.00 & $0.002 *$ \\
\hline $3 \mathrm{~h}$ & 8.43 & 1.23 & 7.12 & 0.74 & 7.82 & 1.42 & $0.095 \mathrm{NS}$ \\
\hline $6 \mathrm{~h}$ & $9.65^{\mathrm{a}}$ & 1.32 & $8.17^{b}$ & 1.09 & $8.33^{b}$ & 1.00 & $0.016^{*}$ \\
\hline $24 \mathrm{~h}$ & $14.40^{\mathrm{a}}$ & 1.67 & $11.50^{b}$ & 1.12 & $9.12^{c}$ & 0.92 & $\leq 0.001$ * \\
\hline $48 \mathrm{~h}$ & $19.16^{\mathrm{a}}$ & 1.72 & $12.98^{b}$ & 1.10 & $10.42^{c}$ & 0.73 & $\leq 0.001$ * \\
\hline $72 \mathrm{~h}$ & $21.30^{a}$ & 1.21 & $15.36^{\mathrm{b}}$ & 0.71 & $11.60^{\mathrm{c}}$ & 0.99 & $\leq 0.001$ * \\
\hline 7 days & $23.91^{\mathrm{a}}$ & 1.94 & $18.55^{b}$ & 0.77 & $13.04^{\mathrm{c}}$ & 0.83 & $\leq 0.001$ * \\
\hline 10 days & $27.94^{\mathrm{a}}$ & 1.18 & $21.63^{b}$ & 0.58 & $12.74^{\mathrm{c}}$ & 0.72 & $\leq 0.001$ * \\
\hline 14 days & $27.52^{\mathrm{a}}$ & 1.15 & $25.67^{b}$ & 0.45 & $13.96^{\mathrm{c}}$ & 1.12 & $\leq 0.001 *$ \\
\hline
\end{tabular}

Means with the same letter $(\mathrm{a}, \mathrm{b}$ or $\mathrm{c})$ within each row are not significant (NS), and $\left(^{*}\right)$ means significant at $p>0.05$.

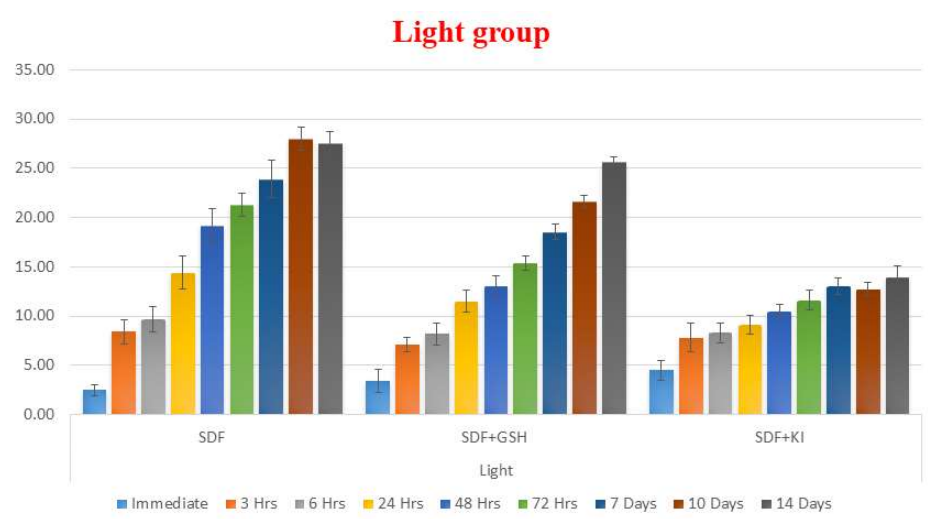

Figure 3. Bar chart showing mean $\Delta \mathrm{E}$ for different tested groups for dentin substrate within each time interval under light exposed conditions. 
Regarding the dark stored dentin group, the same pattern was noticed as the group exposed to light, but with a lower scale of $\Delta \mathrm{E}$ values (Table 4 and Figure 4).

Table 4. Mean and SD for $\Delta \mathrm{E}$ for different tested groups at all of the time intervals within dentin under dark conditions.

\begin{tabular}{|c|c|c|c|c|c|c|c|}
\hline \multirow{3}{*}{ Dentin } & \multicolumn{6}{|c|}{ Dark } & \multirow{3}{*}{$p$-Value } \\
\hline & \multicolumn{2}{|c|}{ SDF } & \multicolumn{2}{|c|}{$\mathrm{SDF}+\mathrm{GSH}$} & \multicolumn{2}{|c|}{ SDF + KI } & \\
\hline & Mean & SD & Mean & SD & Mean & SD & \\
\hline Immediate & 2.05 & 0.61 & 2.99 & 0.91 & 2.69 & 1.43 & $0.129 \mathrm{NS}$ \\
\hline $3 \mathrm{~h}$ & 6.12 & 2.18 & 5.14 & 1.15 & 6.57 & 1.64 & $0.268 \mathrm{NS}$ \\
\hline $6 \mathrm{~h}$ & $8.45^{\mathrm{a}}$ & 0.84 & $5.52^{b}$ & 1.28 & $8.00^{\mathrm{a}}$ & 1.04 & $\leq 0.001 *$ \\
\hline $24 \mathrm{~h}$ & $10.30^{a}$ & 0.80 & $7.72^{\mathrm{c}}$ & 0.73 & $8.84^{b}$ & 0.86 & $\leq 0.001$ * \\
\hline $48 \mathrm{~h}$ & $11.64^{\mathrm{a}}$ & 1.04 & $9.87^{\mathrm{b}}$ & 0.84 & $9.64^{b}$ & 0.55 & $\leq 0.001$ * \\
\hline $72 \mathrm{~h}$ & $13.32^{a}$ & 1.11 & $12.36^{\mathrm{b}}$ & 0.66 & $10.69^{c}$ & 0.76 & $\leq 0.001$ * \\
\hline 7 days & $15.96^{\mathrm{a}}$ & 0.57 & $15.69^{\mathrm{a}}$ & 0.91 & $12.54^{b}$ & 0.91 & $\leq 0.001$ * \\
\hline 10 days & $19.32^{\mathrm{a}}$ & 0.54 & $18.62^{b}$ & 0.37 & $12.84^{\mathrm{c}}$ & 0.85 & $\leq 0.001 *$ \\
\hline 14 days & $22.29^{a}$ & 00.81 & $20.90^{b}$ & 0.82 & $13.61^{c}$ & 1.02 & $\leq 0.001$ * \\
\hline
\end{tabular}

Means with the same letter $(\mathrm{a}, \mathrm{b}$ or $\mathrm{c})$ within each row are not significant $(\mathrm{NS})$, and $\left.{ }^{*}\right)$ means significant at $p>0.05$.

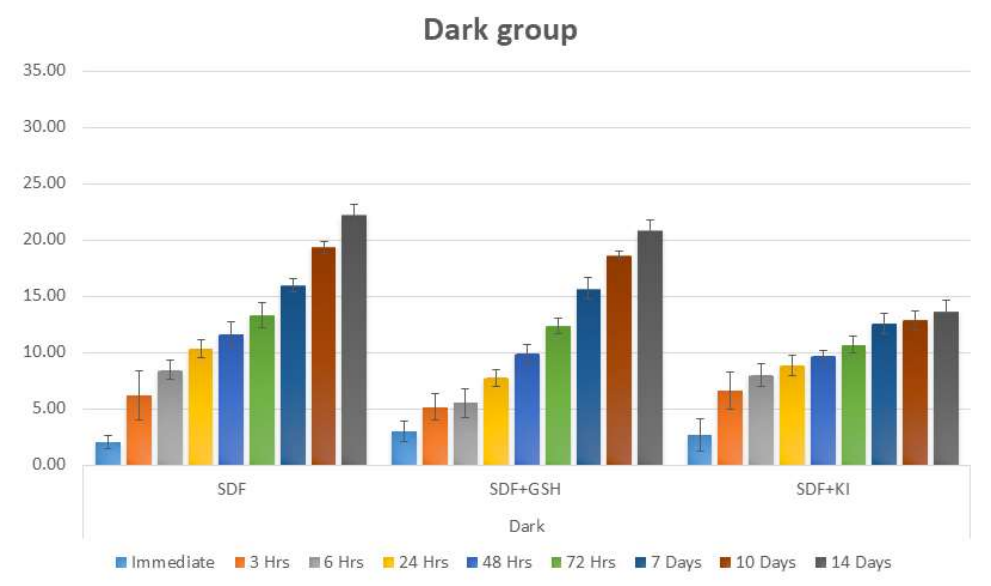

Figure 4. Bar chart showing mean $\Delta \mathrm{E}$ for different tested groups for dentin substrate within each time interval under dark conditions.

\subsection{SEM Observation Results}

For the SDF enamel group, the SEM image showed small (less than a micrometer) separate crystals distributed over the surface while after 2 weeks the image showed greater aggregation of crystals of a larger size which were spread over the whole surface (Figure 5a,b). The SDF + GSH enamel group did not show any crystal formation after $24 \mathrm{~h}$, however by 2 weeks crystal formation had occurred and displayed a radial branching pattern (Figure $5 c, d$ ). The SDF + KI enamel group showed very few crystals after $24 \mathrm{~h}$, however like the other groups by 2 weeks there was a noticeable increase in crystal formation over the surface (Figure 5e,f). 

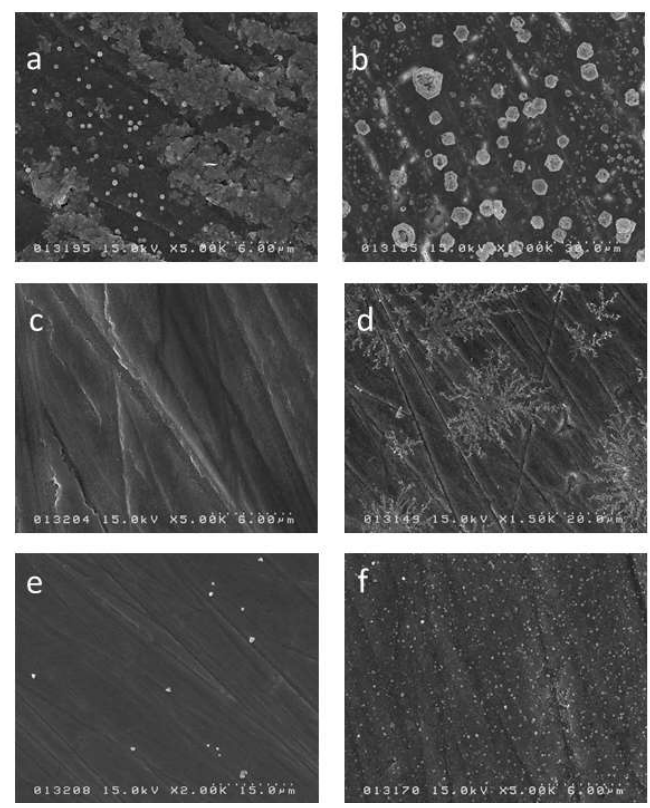

Figure 5. Scanning electron microscope (SEM) image for the surface of the enamel specimens: (a) SDF $24 \mathrm{~h}$; (b) SDF 2 weeks; (c) SDF + GSH 24 h; (d) SDF + GSH 2 weeks; (e) SDF + KI 24 h; and (f) SDF + KI 2 weeks.

Regarding the SDF dentin group, the SEM image showed sparse crystal formation on the surface and associated dentinal tubule occlusion, while at 2 weeks the dentin surface had larger crystal formation but this remained sparse (Figure 6a,b). The SDF + GSH dentin group showed partial occlusion of dentinal tubules with no crystal formation on surface, but at 2 weeks, crystal formation was observed over the whole surface (Figure $6 c, d$ ). The SDF + KI dentin group showed very few crystals over the surface and only partial occlusion of the dentinal tubules, while at 2 weeks the crystal formation had increased in frequency and size (Figure 6e,f).
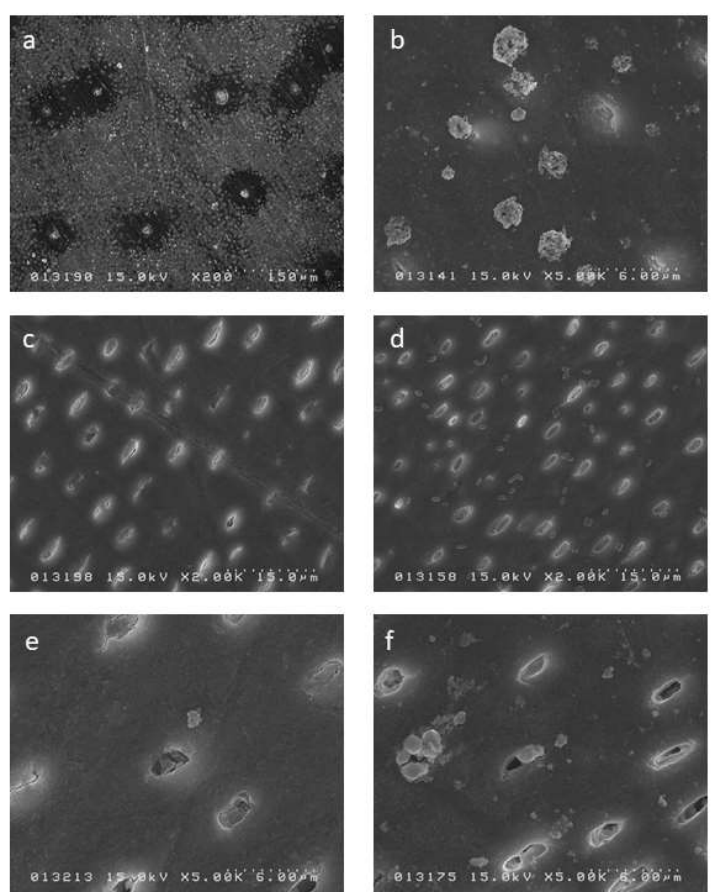

Figure 6. SEM image for the surface of the dentin specimens: (a) SDF 24 h; (b) SDF 2 weeks; (c) SDF + GSH 24 h; (d) SDF + GSH 2 weeks; (e) SDF + KI 24 h; and (f) SDF + KI 2 weeks. 
Regarding the pattern of crystal formation at higher magnification, the SDF group showed typical cubic-shaped crystals (Figure 7a), the SDF + GSH group showed branching or radial-shaped aggregations of crystals (Figure $7 \mathrm{~b}$ ), while the SDF + KI group showed irregular-shaped crystal formation (Figure 7c).
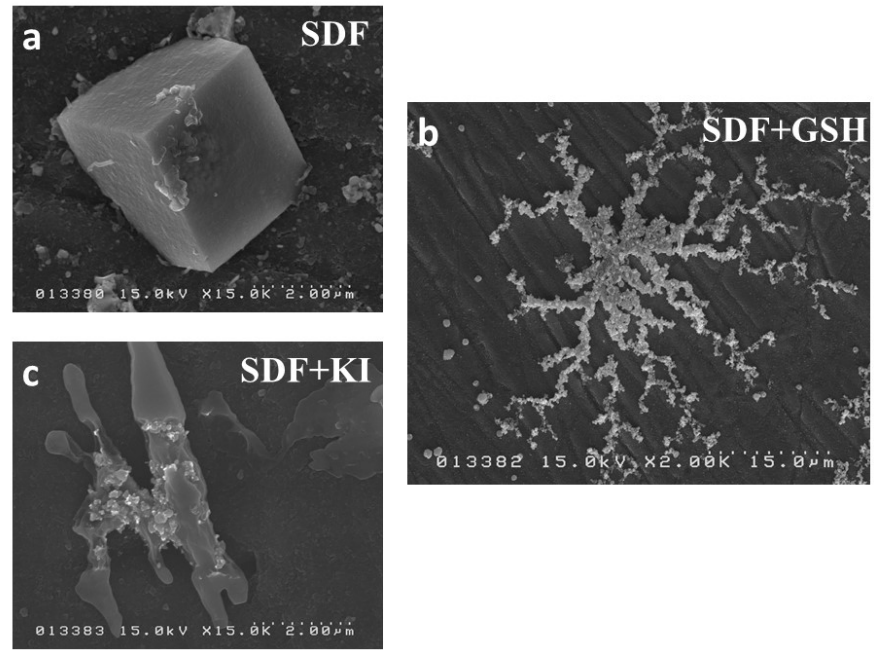

Figure 7. SEM image for the pattern of crystal formation: (a) SDF group; (b) SDF + GSH group; and (c) SDF + KI group.

\subsection{EDS Elemental Analysis}

The EDS point analysis for the crystals formed in both the SDF group and the SDF + GSH group showed a high peak of silver, confirming that the crystals were silver (Figure 8a), while the SDF + KI group showed the highest peak for silver followed by iodine, confirming presence of silver iodide (Figure 8b).
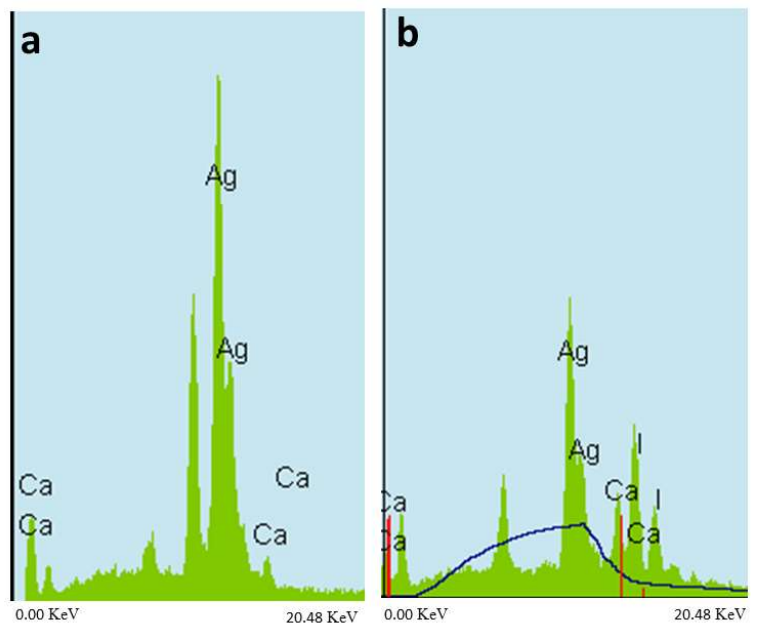

Figure 8. Energy dispersive X-ray spectroscopy (EDS) analysis: (a) SDF and SDF + GSH group and (b) SDF + KI group.

\section{Discussion}

SDF is a colorless solution that contains a high concentration of fluoride $(44,880 \mathrm{ppm})$ and silver (25.5\%). Upon application of SDF, it reacts with tooth structure to release a large quantity of free silver ions $\left(\mathrm{Ag}^{+}\right)$. When these ions are reduced, they aggregate and precipitate resulting in the formation of 
dark stains on the tooth surface, which has caused esthetic concerns among practitioners and patients alike [15]. Since SDF is sensitive to light which leads to surface color changes on tooth structure, a spectrophotometer was chosen to measure the color changes as it is able to record and measure the full visible spectrum for analysis [16]. A spectrophotometer is a sophisticated digital instrument, which can measure the complex color of tooth structure numerically with high reliability and reproducibility [16].

Potassium iodide was introduced in an attempt to solve the color change problem associated with SDF. Upon application of a saturated solution of potassium iodide immediately after SDF application, silver iodide crystals are formed and precipitate on the surface as a creamy white precipitate [9]. The reaction between $\mathrm{KI}$ and SDF is depicted as:

$$
\mathrm{Ag}\left(\mathrm{NH}_{3}\right)_{2} \mathrm{~F}+\mathrm{KI} \rightarrow \mathrm{AgI}+\mathrm{KF}+2 \mathrm{NH}_{3}
$$

Glutathione (GSH) is a tri-peptide biomolecule and considered the best candidate with silver as it contains a thiol group (-SH) which has a high affinity for adsorption onto metal surfaces [17]. GSH forms a coat around silver particles, decreasing the aggregation of silver particles as well as controlling the rate of silver ion release (Homeostasis) [14], which may play a role in decreasing the rate of color changes of an SDF-coated tooth surface over time.

As bovine teeth are reported to resemble human teeth in many features including radio-density [18], dentin surface roughness and even more homogeneity in respect to mineral composition compared with human teeth [19]. It was considered beneficial to use bovine teeth for the evaluation of color in order to eliminate as many confounding variabilities as possible among the enamel and dentin specimens. Caries-free dentin and enamel specimens were used in this study, as the purpose was to test staining of SDF as a preventive agent.

In case of enamel, silver $\left(\mathrm{Ag}^{+}\right)$and fluoride $\left(\mathrm{F}^{-}\right)$ions released from SDF can penetrate the surface up to $25 \mu \mathrm{m}$ [20], and react with enamel to form mainly calcium fluoride $\left(\mathrm{CaF}_{2}\right)$, silver phosphate $\left(\mathrm{Ag}_{3} \mathrm{PO}_{4}\right)$ and a small quantity of metallic silver [21]. While in the case of dentin, the silver and fluoride ions are able to penetrate as much as 50-200 $\mu \mathrm{m}$ into the dentin, and react with the it to form mainly metallic silver attached to protein (silver protein) [21] as well as $\mathrm{CaF}_{2}$, and $\mathrm{Ag}_{3} \mathrm{PO}_{4}$ in a lesser amount [8].

Silver phosphate $\left(\mathrm{Ag}_{3} \mathrm{PO}_{4}\right)$ crystals are yellow in color once formed and gradually turn dark, especially if exposed to light as the silver ions are released and reduced to metallic silver [21].

As most of the free silver ions have already reacted with the iodine salt (KI) that may be the reason for the insignificant change in color between different time intervals in this study when the tooth substrates were treated with the SDF + KI solution. However, other studies have reported significant color changes after long term storage $[10,22,23]$.

The GSH group demonstrated a significant decrease in color changes in enamel, which showed only a slight change in color changes, whereas the change in color for dentin was slightly greater color changes. This may be because the formation of metallic silver was much less on enamel than dentin and the percentage of " $20 \%$ " GSH was sufficient for enamel to minimize color changes, but for dentin it seems necessary to use an increased concentration of GSH to more effectively reduce color changes.

According to the results of the current study, GSH was more effective in reducing color changes of enamel and dentin, therefore the null hypothesis was rejected.

In this study, we mixed SDF with $20 \%$ GSH by weight. We were not able to increase the percentage of GSH to more than $20 \%$ as it was difficult to dissolve the GSH in SDF. May be with this percentage of (20\%) GSH, it was difficult to completely coat all of the silver particles.

The ability of GSH to decrease the color changes of enamel and dentin may encourage the use of SDF in a greater variety of clinical situations with better esthetic outcomes than SDF alone.

Further studies are needed to better understand simpler ways on how to increase the GSH concentration in currently used SDF solutions. 


\section{Materials and Methods}

This study protocol was approved by the ethics committee of Tokyo Medical and Dental University (11 December 2017) with identification code "D2013-022-02" (Institutional Research Board approval number: 725)

\subsection{Specimens Preparation}

One hundred and twenty bovine teeth specimens, free of cracks or caries (sixty enamel and sixty dentin) were used. Enamel specimens $(6 \times 6 \mathrm{~mm})$ were prepared from the labial surface of bovine incisor crowns, while dentin blocks $(6 \times 6 \mathrm{~mm})$ were prepared from the labial and lingual surfaces of the cervical portion of bovine incisor roots. The specimens were cut using a low-speed diamond saw (IsoMet 1000, Buehler Ltd., Lake Bluff, IL, USA) under water coolant. Specimens were embedded in acrylic resin (Unifast III, GC, Tokyo, Japan) and the surfaces were successively ground flat using 600-2000-grit silicon carbide papers (SiC) (Fuji Star, Sankyo Rikagaku, Saitama, Japan) under running water. The specimens were then ultra-sonicated in distilled water (DW) (Milli-Q water; Millipore, Billerica, MA, USA).

For each of the enamel and dentin groups, the specimens were randomly divided into three groups according to solution application. The first group received SDF treatment as a control group, the second group received SDF followed by application of a potassium iodide solution $(2.36 \mathrm{~mol} / \mathrm{L})$, while the third group received SDF mixed with $20 \%$ GSH (Table 5).

Table 5. Materials.

\begin{tabular}{|c|c|c|c|}
\hline Code & Materials & Composition & Manufacturer \\
\hline SDF & Saforide & $\begin{array}{c}38 \% \text { Silver diamine fluoride } \\
\mathrm{F}=44,880 \mathrm{ppm}, \mathrm{Ag}=253,870 \mathrm{ppm}\end{array}$ & Bee Brand Medico Dental, Osaka, Japan \\
\hline $\begin{array}{c}\text { KI } \\
\text { GSH }\end{array}$ & $\begin{array}{l}\text { Potassium Iodide (KI) } \\
\text { Glutathione }\end{array}$ & $\begin{array}{l}\text { White, crystalline powder of KI } \\
\text { l-Glutathione reduced }\end{array}$ & $\begin{array}{c}\text { Wako Pure Chemical Industries, Osaka, Japan } \\
\text { Sigma-Aldrich, St. Louis, MO, USA }\end{array}$ \\
\hline
\end{tabular}

\subsection{Material Application}

Materials were applied according to manufacturer instructions.

1- Thirty-eight percent SDF: applied to the tooth surface and agitated using a micro-brush for $1 \mathrm{~min}$, left for $2 \mathrm{~min}$ and rinsed with a copious amount of distilled water for $30 \mathrm{~s}$;

2- SDF followed by KI: SDF was applied to the tooth surface, immediately followed by application of a saturated KI solution until creamy white precipitates turned clear, then washed with copious amounts of distilled water for $30 \mathrm{~s}$; and,

3- SDF mixed with $20 \%$ GSH: under vigorous stirring, SDF was mixed with $20 \%$ GSH by weight until the solution was clear without any precipitates. Then applied in the same manner as the SDF.

Each group was divided into two subgroups according to light exposure namely, light and dark subgroups $(n=10)$. The light groups were kept in clear containers and exposed continuously to a fluorescent light source (FBL18EXL, Mitsubishi, 18W, Tokyo, Japan) with an intensity of approximately $4 \mathrm{mWatts} / \mathrm{cm}^{2}$ and wavelength $410-460 \mathrm{~nm}$, while the dark groups were kept in lightproof containers. All specimens were incubated at $37^{\circ} \mathrm{C}$.

\subsection{Color Assessment}

Color assessments of the specimens $(n=10)$ were recorded at ten time-interval points: baseline (before solution application), immediately after solution application, 3, 6, 24, 48, 72 h, and 7, 10, 14 days after application. Color was recorded using a spectrophotometer (JP7200F, Juki, Tokyo, Japan) with a wave length range of $400-700 \mathrm{~nm}$. The instrument was calibrated before each examination time according to the manufacturer's instructions. Each color was explained using the 3-dimensional 
CIELAB color space system (frequently denoted as $L^{*} a^{*} b^{*}$ ), where $L^{*}$ represents brightness ranging from dark (0) to bright $(100)$, $a^{*}$ describes red $\left(+a^{*}\right)$ to green $\left(-a^{*}\right)$, and the $b^{*}$ represents yellow $\left(+b^{*}\right)$ to blue $\left(-b^{*}\right)$. A single operator repeated color measurements three times for each specimen at each time interval and the mean values recorded.

The color difference $(\Delta \mathrm{E})$ of each specimen between baseline and each time-interval point was calculated using the following equation [24];

$$
\Delta \mathrm{E}=\left[(\Delta \mathrm{L})^{2}+(\Delta \mathrm{a})^{2}+(\Delta \mathrm{b})^{2}\right]^{1 / 2}
$$

\section{4. .Morphology Observation}

For morphological analysis of the crystals formed on specimen surfaces after solution application, a further eight samples were prepared for each group and treated in the same manner described for specimen preparation for the color measurement. Half of the specimens for each treatment group were observed after $24 \mathrm{~h}$ and the remaining half were observed after 2 weeks. Specimens were sputter-coated with osmium ( $4 \mathrm{~nm}$ layer thickness). The surfaces of the prepared specimens were examined under a scanning electron microscope (SEM, H-4500, Hitachi High-Technologies Corporation, Tokyo, Japan) under operating conditions of $15 \mathrm{kV}$.

\subsection{Elemental Analysis}

For elemental analysis of the treated surfaces, five additional specimens were prepared for each treatment group and prepared in the same manner described for specimen preparation for the color measurement and analyzed after 2 weeks. The specimens were sputter-coated with osmium $(4 \mathrm{~nm}$ layer thickness). The elemental point analysis for the surfaces of the specimens was performed to detect phosphorous $(\mathrm{P})$, calcium $(\mathrm{Ca})$, silver $(\mathrm{Ag})$ and iodine $(\mathrm{I})$ ion levels via energy dispersive X-ray spectroscopy (EDS) under a scanning electron microscope (H-4500, Hitachi High-Technologies Corporation, Tokyo, Japan) under operating conditions of $15 \mathrm{kV}$.

\subsection{Statistical Analysis}

Data were analyzed for normality using the Kolmogorov-Smirnov and Shapiro-Wilk tests. Repeated Measures ANOVA test was used to compare the effect of the different materials and time intervals on mean $\Delta \mathrm{E}$. The test was followed by pairwise comparison with Bonferroni correction. The significance level was set at $p \leq 0.05$. Mauchly's and greenhouse tests were applied. Statistical analysis was performed using IBM $^{\circledR}$ SPSS $^{\circledR}$ (SPSS Inc., IBM Corporation, Armonk, NY, USA) Statistics Version 23 for Windows.

\section{Conclusions}

Glutathione bio-molecule has an effect in decreasing tooth surface color changes after application of SDF, especially on enamel and to a lesser extent on dentin.

Author Contributions: N.M. and N.H. conceived and designed the experiments. M.S. performed the experiments, analyzed data and wrote the paper. T.N. and M.F.B. revised the paper. T.N. and J.T. supervised the work. All authors read and approved the final manuscript. All authors have approved the submitted version.

Acknowledgments: The authors thank Ahmed Abdou for his statistical support. This research was supported by the Japan Society for the Promotion of Sciences (16H05515).

Conflicts of Interest: The authors declare no conflict of interest.

\section{References}

1. Shah, S.; Bhaskar, V.; Venkataraghavan, K.; Choudhary, P.; Ganesh, M.; Trivedi, K. Efficacy of silver diamine fluoride as an antibacterial as well as antiplaque agent compared to fluoride varnish and acidulated phosphate fluoride gel: An in vivo study. Indian J. Dent. Res. 2013, 24, 575-581. [CrossRef] [PubMed] 
2. Burns, J.; Hollands, K. Nano Silver Fluoride for preventing caries. Evid. Based Dent. 2015, 16, 8-9. [CrossRef] [PubMed]

3. Peng, J.J.; Botelho, M.G.; Matinlinna, J.P. Silver compounds used in dentistry for caries management: A review. J. Dent. 2012, 40, 531-541. [CrossRef] [PubMed]

4. Suzuki, T.; Nishida, M.; Sobue, S.; Moriwaki, Y. Effects of diammine silver fluoride on tooth enamel. J. Osaka Univ. Dent. Sch. 1974, 14, 61-72. [PubMed]

5. Savas, S.; Kucukyilmaz, E.; Celik, E.U.; Ates, M. Effects of different antibacterial agents on enamel in a biofilm caries model. J. Oral Sci. 2015, 57, 367-372. [CrossRef] [PubMed]

6. Gao, S.S.; Zhang, S.; Mei, M.L.; Lo, E.C.; Chu, C.H. Caries remineralisation and arresting effect in children by professionally applied fluoride treatment-A systematic review. BMC Oral Health. 2016, 16. [CrossRef] [PubMed]

7. Rosenblatt, A.; Stamford, T.C.; Niederman, R. Silver diamine fluoride: A caries "silver-fluoride bullet". J. Dent. Res. 2009, 88, 116-125. [CrossRef] [PubMed]

8. Mei, M.L.; Ito, L.; Cao, Y.; Li, Q.L.; Lo, E.C.; Chu, C.H. Inhibitory effect of silver diamine fluoride on dentine demineralisation and collagen degradation. J. Dent. 2013, 41, 809-817. [CrossRef] [PubMed]

9. Knight, G.M.; McIntyre, J.M.; Craig, G.G.; Mulyani; Zilm, P.S.; Gully, N.J. Inability to form a biofilm of Streptococcus mutans on silver fluoride- and potassium iodide-treated demineralized dentin. Quintessence Int. 2009, 40, 155-161. [PubMed]

10. Li, R.; Lo, E.C.; Liu, B.Y.; Wong, M.C.; Chu, C.H. Randomized clinical trial on arresting dental root caries through silver diammine fluoride applications in community-dwelling elders. J. Dent. 2016, 51, 15-20. [CrossRef] [PubMed]

11. Zhao, I.S.; Mei, M.L.; Burrow, M.F.; Lo, E.C.; Chu, C.H. Effect of Silver Diamine Fluoride and Potassium Iodide Treatment on Secondary Caries Prevention and Tooth Discolouration in Cervical Glass Ionomer Cement Restoration. Int. J. Mol. Sci. 2017, 18, 340. [CrossRef] [PubMed]

12. Nassar, M.; Hiraishi, N.; Shimokawa, H.; Tamura, Y.; Otsuki, M.; Kasugai, S.; Ohya, K.; Tagami, J. The inhibition effect of non-protein thiols on dentinal matrix metalloproteinase activity and HEMA cytotoxicity. J. Dent. 2014, 42, 312-318. [CrossRef] [PubMed]

13. Amato, E.; Diaz-Fernandez, Y.A.; Taglietti, A.; Pallavicini, P.; Pasotti, L.; Cucca, L.; Milanese, C.; Grisoli, P.; Dacarro, C.; Fernandez-Hechavarria, J.M.; et al. Synthesis, characterization and antibacterial activity against Gram positive and Gram negative bacteria of biomimetically coated silver nanoparticles. Langmuir 2011, 27, 9165-9173. [CrossRef] [PubMed]

14. Taglietti, A.; Diaz Fernandez, Y.A.; Amato, E.; Cucca, L.; Dacarro, G.; Grisoli, P.; Necchi, V.; Pallavicini, P.; Pasotti, L.; Patrini, M. Antibacterial activity of glutathione-coated silver nanoparticles against Gram positive and Gram negative bacteria. Langmuir 2012, 28, 8140-8148. [CrossRef] [PubMed]

15. Knight, G.M.; McIntyre, J.M.; Craig, G.G.; Mulyani; Zilm, P.S.; Gully, N.J. Differences between normal and demineralized dentine pretreated with silver fluoride and potassium iodide after an in vitro challenge by Streptococcus mutans. Aust. Dent. J. 2007, 52, 16-21. [CrossRef] [PubMed]

16. Rodgers, J.; Thibodeaux, D.; Cui, X.; Martin, V.; Watson, M.; Knowlton, J. Instrumental and operational impacts on spectrophotometer color measurements. J. Cotton Sci. 2008, 12, 287-297.

17. Jozefczak, M.; Remans, T.; Vangronsveld, J.; Cuypers, A. Glutathione is a key player in metal-induced oxidative stress defenses. Int. J. Mol. Sci. 2012, 13, 3145-3175. [CrossRef] [PubMed]

18. Fonseca, R.B.; Haiter-Neto, F.; Carlo, H.L.; Soares, C.J.; Sinhoreti, M.A.; Puppin-Rontani, R.M.; Correr-Sobrinho, L. Radiodensity and hardness of enamel and dentin of human and bovine teeth, varying bovine teeth age. Arch. Oral Biol. 2008, 53, 1023-1029. [CrossRef] [PubMed]

19. Ghisi, A.C.; Kopper, P.M.; Baldasso, F.E.; Sturmer, C.P.; Rossi-Fedele, G.; Steier, L.; de Figueiredo, J.A.; Morgental, R.D.; Vier-Pelisser, F.V. Effect of superoxidized water and sodium hypochlorite, associated or not with EDTA, on organic and inorganic components of bovine root dentin. J. Endod. 2015, 41, 925-930. [CrossRef] [PubMed]

20. Horst, J.A.; Ellenikiotis, H.; Milgrom, P.L. UCSF Protocol for Caries Arrest Using Silver Diamine Fluoride: Rationale, Indications and Consent. J. Calif. Dent. Assoc. 2016, 44, 16-28. [PubMed]

21. Lou, Y.L.; Botelho, M.G.; Darvell, B.W. Reaction of silver diamine [corrected] fluoride with hydroxyapatite and protein. J. Dent. 2011, 39, 612-618. [CrossRef] [PubMed] 
22. Miller, M.B.; Lopez, L.A.; Quock, R.L. Silver diamine fluoride, potassium iodide, and esthetic perception: An in vitro pilot study. Am. J. Dent. 2016, 29, 248-250. [PubMed]

23. Zhao, I.S.; Mei, M.L.; Burrow, M.F.; Lo, E.C.; Chu, C.H. Prevention of secondary caries using silver diamine fluoride treatment and casein phosphopeptide-amorphous calcium phosphate modified glass-ionomer cement. J. Dent. 2017, 57, 38-44. [CrossRef] [PubMed]

24. Besinis, A.; De Peralta, T.; Handy, R.D. Inhibition of biofilm formation and antibacterial properties of a silver nano-coating on human dentine. Nanotoxicology 2014, 8, 745-754. [CrossRef] [PubMed]

(c) 2018 by the authors. Licensee MDPI, Basel, Switzerland. This article is an open access article distributed under the terms and conditions of the Creative Commons Attribution (CC BY) license (http:/ / creativecommons.org/licenses/by/4.0/). 